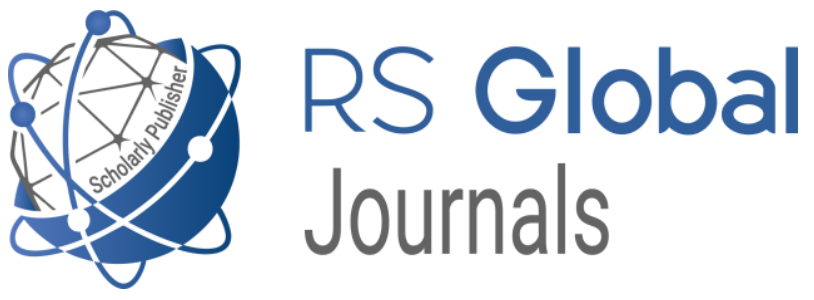

Scholarly Publisher

RS Global Sp. z O.O.

ISNI: 0000000484952390

Dolna 17, Warsaw, Poland 00-773

Tel: +48226022703

Email: editorial_office@rsglobal.pl

JOURNAL International Journal of Innovative Technologies in Social Science

p-ISSN

2544-9338

e-ISSN

2544-9435

PUBLISHER

RS Global Sp. z O.O., Poland

ARTICLE TITLE

THE PROBLEMS OF TEACHING OF THE RUSSIAN

ARTICLE THLE

LANGUAGE AS A FOREIGN LANGUAGE THROUGH

DISTANCE LEARNING (from work experience)

$\operatorname{AUTHOR}(\mathbf{S})$

Musabayova Narmin Chingiz

Musabayova N. Ch. (2020) The Problems of Teaching of the Russian Language as a Foreign Language Through Distance

ARTICLE INFO Learning (from Work Experience). International Journal of Innovative Technologies in Social Science. 6(27).

doi: $10.31435 /$ rsglobal_ijitss/30092020/7155

DOI

https://doi.org/10.31435/rsglobal_ijitss/30092020/7155

RECEIVED

20 July 2020

ACCEPTED

17 August 2020

PUBLISHED

21 August 2020

LICENSE

This work is licensed under a Creative Commons Attribution

4.0 International License.

(C) The author(s) 2020. This publication is an open access article. 


\title{
THE PROBLEMS OF TEACHING OF THE RUSSIAN LANGUAGE AS A FOREIGN LANGUAGE THROUGH DISTANCE LEARNING (from work experience)
}

\author{
Musabayova Narmin Chingiz, \\ assistant professor of the Department of Foreign Languages-2, candidate of Philological Sciences, \\ Baku, Azerbaijan State University of Oil and Industry, Azerbaijan \\ ORCID ID: https://orcid.org/0000-0003-1744-6175
}

DOI: https://doi.org/10.31435/rsglobal_ijitss/30092020/7155

\section{ARTICLE INFO \\ Received 20 July 2020 \\ Accepted 17 August 2020 \\ Published 21 August 2020}

\section{KEYWORDS}

distance learning, Russian as a foreign language, forms of education.

\begin{abstract}
The scientific article deals with the problems encountered in the teaching of Russian as a foreign language to foreign students through distance learning (DL) under conditions of the coronavirus pandemic and quarantine measures taken worldwide. DL has become the only form of education available in many countries of the world. The author speaks about the problems of access of students and teachers to Internet resources, about the selection and use of various Internet platforms in the process of DL. The author shares his experience in organizing and administering lessons, midterms and examinations online. In the article, the author discusses the advantages and disadvantages of DL, the academic, psychological problems of students and teachers, the need for electronic content for each educational programs, ICT competency development courses for teachers and improving DL management. The author sets out the tasks to be carried out by the officials of the Ministry of Education, universities and by teachers ahead of the new school year. The pandemic is ongoing and every effort should be made to use DL in a wider format.
\end{abstract}

Citation: Musabayova N. Ch. (2020) The Problems of Teaching of the Russian Language as a Foreign Language Through Distance Learning (from Work Experience). International Journal of Innovative Technologies in Social Science. 6(27). doi: 10.31435/rsglobal_ijitss/30092020/7155

Copyright: (C) 2020 Musabayova N. Ch. This is an open-access article distributed under the terms of the Creative Commons Attribution License (CC BY). The use, distribution or reproduction in other forums is permitted, provided the original author(s) or licensor are credited and that the original publication in this journal is cited, in accordance with accepted academic practice. No use, distribution or reproduction is permitted which does not comply with these terms.

Введение. Пандемия коронавирусной инфекции, охватившая всю нашу планету, внесла свои коррективы и в процесс обучения учащихся во всем мире. В режиме карантина и самоизоляции особую актуальность приобрело дистанционное обучение (далее - ДО).

Настоящие потребности в дистанционном обучении в Азербайджане начали ощущаться еще в 90-ые годы прошлого века под воздействием целого ряда событий, произошедших в стране и обществе, и в связи с необходимостью сделать систему образования в республике более гибкой, совершенной и отвечающей духу времени. Но при всем при этом отношение общества к использованию ДО в системе традиционного, классического образования остается быть неоднозначным, и многие противники расширения сфер употребления ДО рассматривают последнее лишь в качестве дополнительного, хотя и привлекательного, инструмента получения знаний. События последних месяцев в мире заставили многих деятелей сферы образования пересмотреть свои позиции и взгляды на ДО.

Материалы исследований и полученные результаты. Дистанционное обучение в условиях пандемии стало одной из самых стремительно развивающихся в мире сфер индустрии, которая стимулировала освоение и использование новых информационных, коммуникационных и интерактивных технологий преподавателями и учащимися. Большая нагрузка пала и на властные структуры, которым пришлось включиться в процесс обеспечения 
непрерывности процесса обучения в средней и высшей школе с использованием Интернет ресурсов. Уже в марте 2020 года в условиях жесткого карантина в Азербайджане более 70\% школьников получили доступ к обучению по основным предметам школьной программы с использованием гаджетов, а при отсутствии таковых - к специальным занятиям с помощью услуг телевидения. Более $80 \%$ (в некоторых случаях около $90-96 \%$ ) учащихся университетов было задействовано в занятиях на платформах Microsoft Teams, Zoom, Skype и др.

Практика работы во II семестре 2019/2020 учебного года в школах и университетах Азербайджана (и не только!) обнажила все плюсы и минусы дистанционного обучения как основной формы получения образования.

Здесь мы хотели бы остановиться на реальных проблемах, с которыми пришлось столкнуться преподавателям и студентам-иностранцам, изучающим РКИ на предвузовском этапе обучения в университетах Азербайджана.

Первой проблемой стал выбор Интернет платформы и возможность охвата ею студентов, находившихся как на территории нашей страны, так и за ее пределами. Не все студенты смогли вернуться после зимних каникул в страну обучения в связи с карантином и закрытием границ. Учитывая тот факт, что большая часть иностранцев, обучающихся в Азербайджане, это студенты из стран Азии, то возникла проблема, как привлечь уехавших студентов к процессу онлайн обучения в условиях, когда в некоторых из азиатских стран существуют проблемы с непрерывностью Интернет связи, часто отсутствует возможность бесплатного доступа к Интернет сервисам, в которых можно проводить видеоконференции с большим количеством подключенных пользователей. Существенной представлялась и большая разница в часовых поясах между Баку и местами пребывания студентов. Наиболее удачным в этом плане оказался сервис Skype. Он используется во многих странах, прост в применении, доступна его установка и использование на разных гаджетах в бесплатном режиме. Этот сервис не имеет ограничений по времени пребывания в Интернет пространстве. Программа Skype позволила обеспечить стабильное и неплохое качество изображения и звука, возможность общения во время занятий в чате через голосовую и видеосвязь всем учащимся группы друг с другом и с преподавателем, возможность записи урока на видео и последующее его воспроизведение студентами и преподавателем при необходимости и неограниченное число раз, возможность вставлять презентации, слайд-шоу и другие контенты, вести обмен файлами и т.д.

Второй и самой большой проблемой стала сама организация урока в онлайн режиме. Урок РКИ на удалении сильно отличается от занятия "вживую". В условиях, когда занятие проводится не на родном языке учащегося, а урок представляет собой обучение иностранному языку (РКИ) во многом средствами последнего (русского языка, в данном случае) без привлечения (или частичного привлечения) родного языка и в отсутствии языка-посредника, а также в условиях неоднородности национального состава группы студентов-иностранцев, все проблемы обучения удваиваются, утраиваются... Главная трудность в этой ситуации - это невозможность непосредственного контакта преподавателя с учащимся. "А это порождает следующие проблемы: отсутствие непосредственного и целостного восприятия материала; снижение возможности общения и совместного размышления" и др. [4]

В прошедшем учебном году преподавателям пришлось в спешном порядке, с одной стороны, "самообразовываться", повышать свою информационную культуру, преодолевать психологические трудности, продумывать и организовывать совместную познавательную деятельность со студентами в рамках ДО, а с другой стороны, готовить специальным образом организованные дидактические материалы (новые типы устных и письменных заданий; новые тексты, диалоги, монологи для аудирования и развития навыков говорения; новые видеоролики, таблицы и т.д.), которые можно совместить с имеющимися на руках у студентов базовыми учебниками и учебными пособиями и которые позволяют обучающимся лучше и более качественно усвоить учебный материал в условиях ДО. И здесь встает еще одна важная проблема - это "проблема плагиата" и соблюдения авторских прав на контентные и методические элементы образовательной среды.[4] Разработка курсов дистанционного обучения - это очень трудоёмкая работа. Так, создание 1 часа действительно интерактивного мультимедийного взаимодействия занимает более 1000 часов профессионалов.[2] Поэтому один из путей решения этой проблемы - это поиск и использования существующих в 
свободном доступе в Интернете видео и аудио файлов, их комбинация и адаптация к потребностям учебного процесса, к чему и прибегли многие наши преподаватели.

Реальная работа со студентами-иностранцами в режиме ДО в прошедшем семестре показала невозможность в рамках одного урока РКИ или НСР (80 мин.) освоить объем материала, который без проблем усваивался учащимися при классической форме урока. Преподавателям пришлось пересмотреть порядок, объемы, методы и способы презентации отдельных лексико-грамматических тем по РКИ и НСР. Пришлось прибегнуть к микромодульному обучению - подаче учебного материала небольшими информационными блоками (модулями), так как этот способ презентации позволил облегчить студенту как усвоение и обработку собственно учебного материала, так и дал возможность снизить тревогу учащегося перед обучением; повысить его мотивацию к обучению; моментально проверить собственные знания и навыки и осознать собственные достижения и успехи одногруппников. С целью выполнения учебных планов и программ преподавателям все-таки пришлось сократить и объединить определенные темы, что, конечно, не смогло не сказаться на качестве образования.

В процессе работы преподаватели столкнулись и с рядом других проблем. Из-за недостаточно качественной аудиосвязи, невозможности в полной мере ощутить тембр, интонацию и другие характеристики голоса преподавателя студентам было трудно выполнять фонетические упражнения, писать фонетические диктанты, наблюдались сложности и с адекватным восприятием и выполнением заданий по материалам аудиотекстов, диалогов.

В условиях ДО трудно развивать навыки устной речи учащихся, трудно визуализировать смоделированные преподавателем и студентом ситуации, так как студент видит преподавателя и собеседника не вживую, а с монитора компьютера, не ощущает чувств, эмоций, настроения товарищей; кроме вербальных средств в процессе коммуникации мы нуждаемся и в невербальных средствах общения (мимика, жесты, интонационные паузы и т.д.), к чему мы, конечно, не можем прибегнуть в условиях ДО. Поэтому в процессе работы парами (или с участием нескольких игроков) студенты часто не могут полностью сконцентрировать свое внимание на теме беседы, диалога, вовремя и адекватно подать реплику или дать резюмированный ответ после прослушанного монолога или диалога. Количество предполагаемых участников беседы в условиях ДО приходится лимитировать, приходиться снижать и объём, и уровень сложности аудиоматериалов. Однако ДО позволяет геймифицировать обучение [1], т.е. добавить в образовательный процесс игровых элементов: систему поощрения наиболее активных и успешных учащихся (значки, сертификаты); соревнование в выполнении на время постепенно усложняющихся заданий; создание увлекательного сюжете или запоминающихся персонажей с помощью специального программного обеспечения, анимированных видеороликов и изображений и др.

При работе в режиме ДО следует сказать и об индивидуально-психологической нагрузке на преподавателя и учащегося. Многие преподаватели и студенты изначально не были ни морально, ни психологически готовы полностью перейти на онлайн обучение в условиях пандемии:

- не все участники образовательного процесса располагали персональным компьютером или иными современными дивайсами с доступом в Интернет;

- методологически и методически преподаватели не были готовы к организации своей собственной работы и самостоятельной работы студентов в условиях виртуальной обучающей среды;

- лишь малая часть профессорско-преподавательского состава владела различными инновационными методами инклюзивного обучения и располагала соответствующими учебными материалами;

- студенты не были готовы к самообразованию, самодисциплине в таком большом объеме в условиях нового для них ДО и др.

Все сказанное вызывало стресс, депрессию и другие негативные психологические реакции организма преподавателей и учащихся, которые усугубились в конце учебного года проблемой приема/сдачи зачетов и экзаменов в онлайн режиме.

Именно необходимость проведения итогового контроля в веб-режиме еще больше привлекла внимание к необходимости кардинального решения одной из ключевых проблем 
Интернет-обучения - проблеме аутентификации учащегося при проверки его уровня знаний и сформированности навыков на уровне поэтапного и итогового тестирования.

Преподавателю трудно контролировать работу учащегося во время онлайн занятий и в ходе выполнения домашних работ. Преподаватель не всегда отчетливо видит, сколько студентов и кто именно присутствует на уроке, не всегда в достаточной мере может оценить степень участия студентов на уроке, не знает, какими дивайсами пользуются учащиеся при выполнении заданий, не прибегают ли студенты при подготовке к ответу к помощи других студентов или третьих лиц и др. Последнее очень актуально особенно, когда речь заходит об экзаменах. В этом учебном году на подготовительном отделении иностранные студенты сдавали только один экзамен по НСР и РКИ в онлайн режиме, а обычно 2: 1) письменный экзамен, включающий написание конспекта текста по НСР и развернутые ответы на вопросы, затрагивающие основные положения текста, а также лексико-грамматические задания по РКИ (нейтральный стиль); 2) устный экзамен, состоящий из 4 вопросов: чтение и пересказ текста по НCP; определение научных понятий (дефиниции); выполнение лексико-грамматических тестов; беседа на заданную тему (нейтральный стиль). Успешная сдача обоих экзамена позволяет быть зачисленным на 1 курс бакалавриата. В этом году большие группы студентов были разбиты на подгруппы в составе 6-8 человек (в зависимости от того, на какой интернет платформе проводился экзамен), за прохождением экзамена наблюдала специальная группа ответственных лиц от администрации, которая, подключившись к экзамену, должна была следить за тем, чтобы в ходе экзамена студенты все время находились в поле зрения наблюдателей и экзаменаторов, не прибегали к помощи третьих лиц и дополнительным Интернет ресурсам и другим материалам, так как у учащихся было более месяца на подготовку к экзамену. Во время устного экзамена (записывался на видео) студентам предлагалось назвать номер экзаменационного билета (что документировалось преподавателем в экзаменационной ведомости), затем на индивидуальный адрес электронной почты высылался экзаменационный билет. В связи с тем, что экзамен проводился в новом, незнакомом для студентов, формате онлайн, количество вопросов в билетах было сокращено с 4 до 3 вопросов, отдельные типы вопросов пришлось упростить или заменить.

Экзаменационный билет включал 2 вопроса по курсу НСР и 1 - собственно по Русскому языку (нейтральный стиль):

1. Прочитайте текст по научному стилю речи “...", составьте план текста, ответьте на поставленные вопросы (давалось по 4 вопроса к тексту) $u$ перескажите содержание текста (объем текста с 450-500 слов в эту сессию был уменьшен до 250-300 слов и подвергся дополнительной адаптации)

2. Дайте определение следующему научному понятию "..." (в эту сессию количество дефиниций было снижено с 3 до 1).

3. Проведите беседу на тему "..." (часть беседы - это монолог студента, вторая часть диалог с преподавателями)

Здесь были отмечены некоторые проблемы, возникающие в условиях ДО в качестве основного способа обучения иностранных студентов РКИ, но какие плюсы (а о минусах мы уже поговорили) имеет ДО для иностранных студентов. занятий:

Веб-занятия открывают широкие перспективы перед студентом в течение семестровых

- большие группы учащихся (14-16 чел.) делятся на малые (5-6 чел.) в целях сохранения качества обучения и улучшения усвоения учебного материала;

- преподаватель максимально персонифицирует учебный процесс, стараясь сделать его минимально стрессовым;

- преподаватель и студент больше используют мультимедиа технологии, чем при классическом очном обучении; словарям;

- студент имеет широкий доступ к виртуальным ресурсам, а также быстрый доступ к

- студент может пользоваться бумажными версиями учебников и учебных пособий или открывать учебные материалы на разных типах электронных устройств (на персональном стационарном компьютере, ноутбуке или моноблоке), практические задания выполнять на планшете, а мини-ролики смотреть на телефоне (кроссплатформенность - [1]); 
- учащийся имеет возможность сопоставить свои достижения с успехами товарищей и сделать соответствующие выводы, повысить свою самооценку и рейтинг среди учащихся; и обстановке;

- возможность записать урок на видео и пересмотреть его в более комфортных условиях

- находясь в привычной обстановке и сохраняя привычный образ жизни, получать образование и возможность на удалении консультироваться со своим преподавателем или иным квалифицированным специалистом вне занятий.

Главной положительной чертой ДО является то, что технологии ДО ориентируют студента на самостоятельное и ответственное отношение к учебе, учат добывать знания и применять их в соответствии с жизненной ситуацией. У учащегося формируются навыки самостоятельной работы и делового общения. Студент учится планировать свой рабочий день и последовательность, темп освоения предметов по программе вне зависимости от своего местонахождения. Большой же минус ДО - это отсутствие тесного, прямого, непосредственного общения с преподавателем и одногруппниками. Ничто не заменит прямого человеческого общения и традиционных занятий в аудитории! Однако жизнь диктует нам свои правила. В условиях пандемии и карантинных мер, принятых во многих странах мира, ДО становится единственным способом продолжение получения образования и нам необходимо развивать и совершенствовать технологии ДО. Перед многими учебными заведениями стоит на повестке дня задача - подготовиться к обучению в онлайн режиме и в следующем учебном году, так как велика вероятность не начать учебный год в классах школ и аудиториях университетов.

Выводы. Какие задачи предстоит решить системе образования разных стран и обществу в целом в преддверии нового учебного года?

1. Улучшить Интернет трафик, совершенствовать возможности интернет платформ в целях улучшения качества образования.

2. На уровне учебных заведений улучшить централизованное автоматизированное управление процессом обучения.

3. За счет средств государства и внутренних возможностей учебных заведений обеспечить малоимущих студентов необходимыми дивайсами и другим инструментарием.

4. Заняться подготовкой электронного контента по каждой образовательной программе, содержащего учебно-методические комплексы и электронные библиотеки.

5. Увеличить эвристическую составляющую учебного процесса за счет применения интерактивных форм занятий, мультимедийных обучающих программ.

6. Персонализировать учебные контенты и сделать возможным их многократное применение преподавателями и студентами;

7. Организовать дистанционное обучение преподавателей, заинтересованных в развитии своей ИКТ-компетентности (онлайн-курсы)

\section{ЛИТЕРАТУРА}

1. Артюхова, И. П. (2018), "Основные тенденции развития дистанционного обучения", НПК. Цифровая трансформащия образования. (2018), Минск: ГИАЦ Минобразования, 368-369. Retrieved from http://dtconf.unibel.by/doc/DTE_conference.pdf

2. Завадский А. Ф., Шерынюк И. В. (2018),"Дистанционное образование", НПК. Цифровая трансформация образования. (2018), Минск: ГИАЦ Минобразования, 389-390. Retrieved from http://dtconf.unibel.by/doc/DTE_conference.pdf

3. Калинин, Д.А. (2015), "Трудности, испытываемые преподавателями в условиях дистанционного обучения", Retrieved from https://cyberleninka.ru/article/n/trudnosti-ispytyvaemye-prepodavatelyami-vusloviyah-distantsionnogo-obucheniya

4. Степанов, С.Ю. (2018). "Дистанционное обучение как ресурс развития непрерывного образования: риски и возможности" [STEPANOV S. (2018). Distance learning as a resource of lifelong learning development: risks and opportunities], Непрерьвное образование: XXI век. Вып. 4 (24). - Retrieved from http://dx.doi.org/10.15393/j5.art.2018.4285 